\title{
Label-Free Proteomics Approach Characterizes Plasma Protein Signature of Donor Brain Death
}

Lukac, J.

2019-04

Lukac , J , Saraswat , M , Holmström , E , Dhaygude , K, Joenväärä , S , Krebs , R , Nykänen , A , Renkonen , R \& Lemström , K 2019 , ' Label-Free Proteomics Approach

Characterizes Plasma Protein Signature of Donor Brain Death ' , Journal of Heart and Lung Transplantation, vol. 38 , no. 4, Supplement, pp. S159 . https://doi.org/10.1016/j.healun.2019.01.380

http://hdl.handle.net/10138/313828

https://doi.org/10.1016/j.healun.2019.01.380

cc_by_nc_nd

acceptedVersion

Downloaded from Helda, University of Helsinki institutional repository.

This is an electronic reprint of the original article.

This reprint may differ from the original in pagination and typographic detail.

Please cite the original version. 


\title{
Label-Free Proteomics Approach Characterizes Plasma Protein Signature of Donor Brain Death
}

\author{
Jan Lukac ${ }^{1}$, Mayank Saraswat ${ }^{2}$, Sakari Joenväärä², Emil Holmström ${ }^{1}$, Kishor \\ Dhaygude $^{1}$, Rainer Krebs ${ }^{1}$, Antti Nykänen ${ }^{1,3}$, Risto Renkonen ${ }^{2}$, Karl Lemström ${ }^{1,3}$ \\ ${ }^{1}$ Cardiopulmonary Research Group, \\ Transplantation Laboratory, University of Helsinki, Helsinki, Finland; \\ ${ }^{2}$ Mass Spectrometry Group, \\ Transplantation Laboratory, University of Helsinki, Helsinki, Finland; \\ ${ }^{3}$ Cardiovascular Research Group, \\ Transplantation Laboratory, University of Helsinki, Helsinki, Finland;
}

\begin{abstract}
Purpose: Despite recent advances in donation after circulatory death, transplants from brain-dead donors remain the sole source in heart transplantation $(\mathrm{HTx})$ worldwide. Due to organ shortage, marginal donors are increasingly used and the utilization of transplants becomes markedly more challenging. They undergo invariably brain death that induces a systemic cytokine and catecholamine storm that lead to systemic inflammation, labile hemodynamics, and organ hypoperfusion. Together, these can damage the heart and aggravate later occurring graft injury, and ultimately, compromise graft function. However, the effect of donor brain death on allograft is not well understood.
\end{abstract}

Methods: In a separate prospective, blinded single-center trial, we collected donor plasma samples and relevant clinical patient data from $50 \mathrm{HTx}$ brain-dead donors and as controls plasma samples from age- and gender-matched 23 healthy volunteers. Quantitative label-free proteomics in high definition MSE mode (HDMSE) was carried out on the samples. Various statistical analyses were performed on quantitative proteomics data to obtain the most reliably distinguishing proteins, which classify the donors vs controls.

Results: With two or more unique proteins per identification, 463 proteins were quantified in our pilot study. A complete separation between donors and controls based on a set of 278 proteins ( $p$-value $<0.05$ ) was seen in supervised and unsupervised classification techniques such as orthogonal projections on latent structure-discriminant analysis (OPLS-DA) and self-organizing maps. The set of proteins was studied further with network, pathway and protein-protein interaction analyses. Using OPLS-DA S-plot, we identified a protein set that completely separated donors from healthy individuals.

Conclusion: To our knowledge, we are the first one elucidating the proteomic signature of braindeath in human blood samples with open-label proteomics. We show that brain death alters protein expression, and that these changes are dependent on the donor demographics. The molecular pathway analyses characterize these changes in a systemic perspective. We found a set of plasma proteins that we suggest as a diagnostic blood biomarker panel to detect high risk heart transplants and we believe that we may identify novel treatment targets induced in noxious pathways after brain death. 